\title{
REQUALIFICAÇÃO DA ZONA PORTUÁRIA E USO DO ESPAÇO PÚBLICO NO BAIRRO DO RECIFE, RECIFE-PE
}

\author{
REQUALIFICATION OF THE PORT AREA AND USE OF PUBLIC SPACE IN THE \\ NEIGHBORHOOD OF RECIFE, RECIFE-PE
}

Felipe Ribeiro Gonzaga MARANGONI'1 , Adauto Gomes BARBOSA²

Artigo recebido em 27/05/2020, aceito em 04/06/2020, publicado em 06/10/2020.

Palavras-chave:

Planejamento urbano;

Bairro do Recife;

Grandes projetos

urbanos;

Apropriação do espaço público.

\section{Keywords:}

Urban planning;

Neighborhood of

Recife;

Big urban projects;

Public space

appropriation.

\section{RESUMO}

Diante do processo de degradação do bairro do Recife, projetos de requalificação urbana foram elaborados desde a década de 1970, procurando dotá-lo de novos equipamentos de turismo, lazer e adequá-lo para atividades da economia criativa. 0 presente artigo analisa a implementação do projeto da zona portuária, destacando os equipamentos implantados, os conflitos e contradições referentes ao uso e apropriação do espaço público. Para tanto, faz uma discussão sobre os planos e projetos que 0 antecederam, ressaltando o esforço do poder público e os interesses da iniciativa privada na requalificação desse bairro da área central da cidade. Porém, sua concepção é bastante seletiva, ao priorizar o consumo da classe média. Já a apropriação do espaço público vai à contramão, com a copresença de grupos citadinos "periféricos", que deixam em evidência que o uso do espaço público é um direito à cidade.

\begin{abstract}
Against the degradation process in the Recife neighborhood, urban requalification projects have been drawn up since the 1970s, seeking to endow the neighborhood with new tourism and leisure facilities and adapt it to creative economy activities. This article analyzes the implementation of the project of area port, highlighting the equipment installed, the conflicts and contradictions regarding the use and appropriation of public space. To this end, it discusses the plans and projects that preceded such a project, highlighting the efforts of the publics authorities and the interests of this private sector in the requalification of this neighborhood in the central area in the city. However, its conception is very selective, as it prioritizes middle class consumption. The appropriation of public space, on the other hand, goes against the grain, with the co-presence of "peripheral" city groups, who show that the use of public spaces is a right to the city.
\end{abstract}

\footnotetext{
${ }^{1}$ Geógrafo pelo Instituto Federal de Pernambuco (IFPE) e mestrando em Geografia no Programa de Pós-Graduação em Geografia da Universidade Federal de Pernambuco. E-mail: felipemarangonixd@gmail.com.
}

2 Professor do Instituto Federal de Pernambuco - Campus Recife. E-mail: adautogb@gmail.com 


\section{INTRODUÇÃO}

Encarados como oportunidades de negócio, certos fragmentos da cidade se tornam cada vez mais importantes para a implantação de Grandes Projetos Urbanos (GPU). Lançando mão do planejamento estratégico e em sintonia com os grandes interesses privados, o poder público promove intervenções urbanas que requalificam antigas áreas degradadas para, assim, criar espaços de consumo e lazer segmentados para a classe média. No Recife, áreas de bairros da área central que constituem frentes d'água e com boas condições de infraestrutura urbana e de acessibilidade passaram a ser muito disputadas pelos agentes imobiliários para a implantação de GPU, como o Novo Recife, no Cais José Estelita (bairro de São José) e a Vila Naval, no bairro de Santo Amaro.

É nesse quadro de referência que se enquadra a requalificação da zona portuária do Recife, abrangendo parte do bairro do Recife e do bairro de São José, cujos antigos armazéns do cais do porto estão sendo transformados em equipamentos de turismo, lazer, cultura e escritórios de empresas de Tecnologia da Informação (TI). O GPU em implantação no bairro do Recife aproveitou o contexto de preparação da cidade para a Copa de 2014, e resulta da articulação do poder público estadual com a iniciativa privada, dando origem ao Projeto Porto Novo, que corresponde à parte compreendida pela implantação dos equipamentos públicos, e ao Projeto Porto Novo Recife, relacionado aos equipamentos privados (Figura 1). Na prática, as duas etapas conformam um só projeto, inclusive porque a implantação dos equipamentos privados não seria possível sem a viabilização do poder público. Desse modo, tal semelhança nos nomes não é por acaso, e, assim sendo, o megaempreendimento como todo é aqui denominado GPU da Zona Portuária do Recife.

Diante disso, o presente artigo analisa a implementação desse GPU, na zona portuária do bairro do Recife e num pequeno fragmento do bairro de São José, destacando os usos dos equipamentos instalados (e por instalar), a não inclusão dos agentes locais pelo projeto, e ainda os conflitos surgidos do uso e apropriação do espaço público. Para tanto, faz uma reflexão teórica sobre produção do espaço e espaço público, seguida de breves notas sobre os planos e ações que antecederam as intervenções na zona portuária, para trazer à luz o esforço do Estado e os interesses da iniciativa privada na requalificação desse importante bairro da área central do Recife.

$\mathrm{Na}$ apreciação da requalificação da zona portuária e do uso do espaço público, são destacadas ao menos duas dimensões espaciais propostas por Lefebvre (2007): o espaço concebido e o espaço vivido. A primeira está relacionada com a concepção projetual, que priorizou a demanda de consumidores solventes (sejam eles moradores ou turistas), e a segunda refere-se às práticas de vivência no espaço público do Marco Zero e do calçadão entre os armazéns requalificados e a frente d'água, por grupos de jovens "periféricos", cujo perfil social e práticas são distintos dos consumidores solventes. 


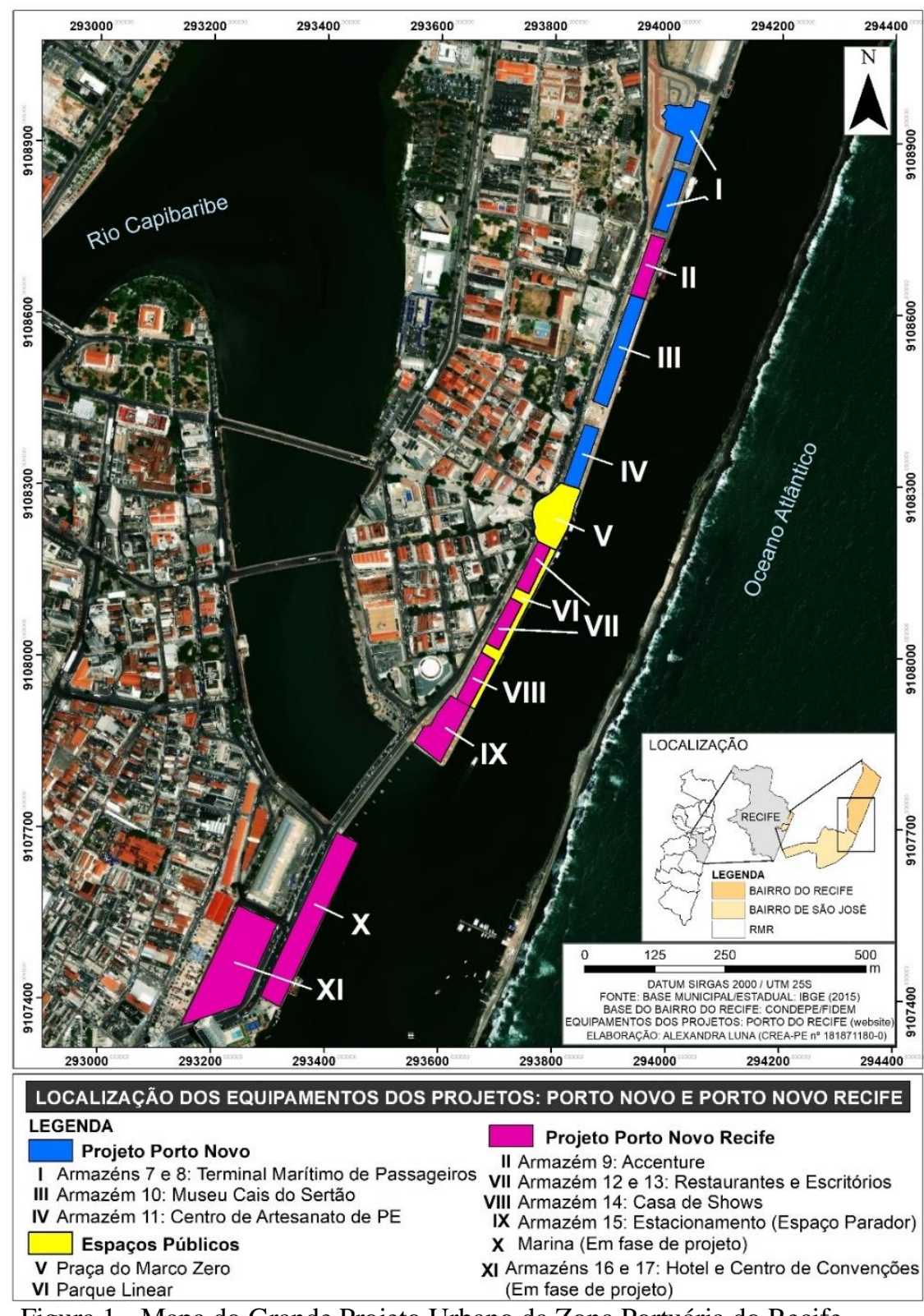

Figura 1 - Mapa do Grande Projeto Urbano da Zona Portuária do Recife.

Dotado de boas condições de infraestrutura urbana, fácil acessibilidade por algumas vias que cortam a área central do Recife e ainda a relativa proximidade com o sítio histórico de Olinda, o bairro do Recife entrou na mira dos investidores como um espaço estratégico da cidade. Atualmente, concentram-se aí equipamentos de lazer e de consumo cultural, além de órgãos públicos e escritórios de empresas de $\mathrm{TI}$ ligadas ao Porto Digital, que reforçam a condição de bairro de atividades terciárias.

As transformações no bairro do Recife são decorrentes de um novo quadro institucional, marcadas pela reforma do Estado e a inclusão do ideário social liberal (Bresser-Pereira, 1998), o que, em termos práticos, resultou em parcerias entre o setor público e o privado para a execução de algumas políticas públicas. No âmbito da gestão estadual, tem havido uma adequação da estrutura administrativa para possibilitar a formulação de políticas que melhor se adequem a esse novo contexto político-institucional. Assim é que a requalificação da zona portuária alinha o objetivo de dar novos usos e funções aos armazéns 
portuários e ter a participação de investidores privados na implementação de empreendimentos (Mendonça, 2014). Vale frisar que tal projeto foi concebido pelo Núcleo Técnico de Operações Urbanas (NTOU), instituição do Governo do Estado de Pernambuco, criada em 2007, integrante da estrutura da Secretaria Estadual de Planejamento e Gestão (SEPLAG), e em 2010 passou para a Secretaria Estadual das Cidades (SECID).

Para além das transformações da dinâmica econômica, vale frisar que a apropriação do espaço público do bairro do Recife se dá por uma pluralidade de agentes sociais, os quais tanto incluem uma demanda solvente para o consumo nos bares, restaurantes e casa noturna, como, também, jovens "periféricos" de baixa renda que igualmente se fazem presentes na cena urbana do bairro. Na prática, considerando a dimensão do espaço concebido, configura-se um território seletivamente requalificado para instalação de novos estabelecimentos de comércio e serviços, voltados para o consumo da classe média. Porém, até como uma forma de resistência, há no âmbito dos espaços públicos abertos uma expressiva frequência de pessoas que fogem a tal perfil, como o segmento LGBTQI+, grupos de dança, praticantes de esportes como capoeira e skate, dentre outros.

De forma distinta dos frequentadores de classe média, no bairro do Recife, esses grupos "periféricos" também procuram exercer, à sua maneira, o uso e a apropriação do espaço público, demonstrando o quão diversas são as formas de sociabilidade urbana. Um importante pressuposto teórico para apreciação da problemática em análise é que, tanto a produção quanto o consumo do espaço, sob a lógica capitalista, não constituem um processo neutro, tendo uma dimensão econômica e sociopolítica (Lefebvre, 2008). Pode-se dizer que há aí distintas territorialidades, nas quais se verificam muitas contradições na apropriação do espaço público na cidade contemporânea, não sendo isso traço exclusivo da capital pernambucana.

Como é muito comum às áreas centrais, em sua maior parte, os frequentadores do bairro do Recife e de seus espaços públicos não são moradores do próprio bairro, e sim turistas e pessoas residentes em outros bairros recifenses e demais cidades da área metropolitana que lá trabalham ou o visitam para fins de lazer e consumo cultural. A sociabilidade urbana nesse bairro, em particular nas áreas que sofreram as intervenções modernizadoras, é eminentemente estabelecida por pessoas que não moram lá, mesmo que persista um núcleo residencial, no caso a Comunidade do Pilar, que a rigor compõe uma unidade espacial praticamente segregada da parte gentrificada do bairro. É evidente que não se trata de uma gentrificação nos moldes dos países europeus e dos Estados Unidos (Bataller \& Botelho, 2012), já que as intervenções urbanas não visam promover novas formas de morar da classe média e se atêm a requalificar o bairro da área central para a instalação de estabelecimentos de consumo e lazer.

O bairro do Recife também está muito associado a serviços decorrentes da presença de órgãos públicos e equipamentos culturais. Lá, estão instalados: sede da Prefeitura Municipal, da Secretaria de Ciência, Tecnologia e Inovação de Pernambuco, do Tribunal Regional Federal da $5^{\text {a }}$ Região, da Receita Federal e da Polícia Federal, dentre outros órgãos públicos. Há ainda equipamentos culturais como a Caixa 
Cultural, o Centro Cultural Correios, a Torre Malakoff, os museus Cais do Sertão e Paço do Frevo e a Sinagoga Kahal Zur Israel, o Centro de Artesanato de Pernambuco, galerias de arte, sedes de grupos de maracatu, dentre outros. Escritórios de empresas do segmento de TI também integram a paisagem do bairro. São bastante comuns ensaios de maracatu, frevo e outras manifestações culturais nas vias públicas ou em alguns recintos fechados, principalmente durante os fins de semana e feriados. Ressalta-se, também, que, desde o início da década de 2000, esse bairro tornou-se o principal espaço do carnaval recifense, tendo 0 maior palco instalado na Praça Rio Branco (ou Praça do Marco Zero, como é popularmente conhecida) e palcos menores em outros pontos, além de desfile de troças e agremiações por várias de suas ruas.

Em meio a toda essa dinâmica espacial, esse bairro tem sido estudado por diversos autores que analisaram diferentes aspectos da realidade urbana e deixam evidente a sua importância, seja do ponto de vista das manifestações culturais, seja dos planos de revitalização. A propósito disso, Lacerda (2007) traz à tona o desvirtuamento das intervenções urbanas no bairro do Recife, as quais teriam se aproximado das tendências do city marketing, ao potencializar a valorização do solo urbano e reforçar as contradições socioespaciais. Lacerda \& Fernandes (2015) ressaltam a valorização imobiliária das áreas incorporadas pelos parques tecnológicos ao se instalarem em áreas históricas degradadas, e discutem como o Porto Digital tem se tornado um importante agente imobiliário e a principal força da iniciativa privada atuante no bairro.

Igualmente adotando um tom crítico-reflexivo, Nery \& Castilho (2008) demonstram que o Plano de Revitalização do Bairro do Recife da década de 1990 não propunha melhorias efetivas para a Comunidade do Pilar, pois tinha um viés eminentemente econômico e priorizava outras zonas do bairro que eram alvo dos interesses da iniciativa privada, numa perspectiva de gentrificação. Por último e tratando das intervenções mais recentes, Souza \& Cavalcanti (2013) analisam o escopo do Estado social liberal nos termos pensados por Bresser-Pereira (1998) e como isso se correlaciona com o planejamento urbano, trazendo à tona o caso do Projeto Porto Novo Recife. Com linha de abordagem semelhante, Mendonça (2014) estuda os GPUs nas áreas de interesse histórico de Recife e Olinda e discute as mudanças no ambiente institucional ensejadas pela reforma do Estado e os seus rebatimentos no planejamento urbano do Recife, inclusive, enfocando 0 Projeto Porto Novo Recife. Como se nota, tais estudos colocam em evidência como tal bairro se tornou um espaço estratégico para o capital e tem sido reestruturado à medida que novas intervenções urbanas são projetadas para a área central do Recife.

Sem perder de vista esses olhares produzidos sobre o bairro do Recife, o presente artigo busca contribuir com a reflexão sobre as intervenções para a requalificação não propriamente sob o viés do planejamento urbano em si, mas como elas ensejam interações sociais relacionadas ao uso e apropriação do espaço público do bairro. As intervenções urbanas também designam o interesse pela acumulação do capital, notadamente de empresas dos ramos da construção civil e de lazer que se beneficiam diretamente por meio da sua implantação. Assim, ao mesmo tempo em que são enxergados certos aspectos positivos, como a instalação de equipamentos culturais e a recuperação de estruturas arquitetônicas outrora degradadas, 0 
presente artigo critica o caráter de seletividade espacial presente nessas intervenções. Se há distinção entre o espaço concebido e o vivido (Lefebvre, 2007), nem sempre o que é projetado para um determinado fim se confirma na prática cotidiana de apropriação, sobretudo quando se trata do espaço público. Enfim, o artigo mostra que o bairro do Recife é um "mar" de contradições e de possibilidades, sendo muito relevante refletir a esse respeito. Fica, portanto, aqui o convite para prosseguir na leitura.

\section{BREVES NOTAS TEÓRICAS SOBRE PRODUÇÃO DO ESPAÇO E ESPAÇO PÚBLICO}

A produção do espaço abarca múltiplos interesses, disputas, desejos e por vezes comportamentos e modos de vida dos agentes envolvidos nesse processo. Sob esse olhar, o espaço é encarado como uma importante dimensão da sociedade e seu processo de produção expressa a dinâmica e as contradições típicas do modo de produção capitalista. Na verdade, tal como afirma Lefebvre (2008), como não existe sociedade sem espaço, este deve ser considerado uma instância social e produzir espaço envolve as relações de produção no âmbito da sociedade.

Ainda segundo esse autor, a produção do espaço se dá em sentido lato, envolvendo aspectos imateriais, desejos e necessidades, como também pode ocorrer em sentido estrito, ou seja, como produção material propriamente dita, relacionada à esfera econômica. Dessa forma, a produção espacial tem tanto uma dimensão imaterial, relacionada com desejos, interesses econômicos, signos de riqueza, lutas e ativismos sociais, quanto uma dimensão concreta, referente a edificações, vias de tráfegos, praças e outros objetos espaciais. Os objetos espaciais que compõem a paisagem tanto expressam a riqueza e a pobreza econômica em termos materiais, como também evocam simbolismos e representações de ambas. A produção do espaço sob o signo do capitalismo é, desse modo, contradição pura.

Trata-se de um processo bastante desigual, na medida em que nem todos os agentes sociais têm as mesmas possibilidades efetivas de agir e transformar o espaço onde vive. De acordo com Carlos (2001), uma contradição central no contexto capitalista é que o espaço é produzido coletivamente, mas sua apropriação está atrelada à lógica da propriedade privada. Assim, o espaço urbano, por exemplo, converte-se numa mercadoria de grande valor no contexto do mercado imobiliário. Isso faz com que a cidade seja encarada como negócio, ainda mais quando fragmentos de bairros ou às vezes bairros inteiros se tornam espaços com grande potencialidade para a implantação de novos empreendimentos econômicos.

Na produção do espaço, há um jogo dialético movido por diferentes interesses e por isso gerador de conflitos. Quanto maiores são as contradições na cidade capitalista, maiores tendem a ser os conflitos de interesses entre os agentes produtores do espaço, particularmente entre os que pensam e agem na cidade encarando-a como lócus de negócio e os que, de forma distinta, a veem como um espaço do encontro, da reunião e da festa, nos termos pensados por Lefebvre (2001). Tal conflito parece muito evidente no bairro do 
Recife, envolvendo interesses empresariais e de muitos usadores ${ }^{3}$ dos espaços públicos, para os quais são impostas restrições a práticas espaciais, por não se enquadrarem no perfil do consumidor de classe média4.

O Estado, por sua vez, constitui-se de representantes da sociedade para melhor viabilizá-la e geri-la com êxito para que objetivos coletivos sejam alcançados, sendo assim, tais representantes fazem parte da minoria ideologicamente dominante. Sobre isso, Poulantzas (1979, p. 27) diz que "La ideología dominante, en particular, consiste en un poder esencial de la clase dominante [...] se encarna en los aparatos del Estado que desempeñan el papel de elaborar, inculcar y reproducir esa ideología". Uma ideologia representa um sistema de ideias e ou representações, assim como práticas sociais que modificam costumes e hábitos para se adequar a sistemas dominantes. As ideologias apregoadas pela classe dominante estão imbricadas no Estado, fazendo com que seus interesses sejam legitimados socialmente e materializados. Sobre o Estado capitalista, 0 autor em contexto ainda contribui dizendo que

[...] es cierto que el Estado capitalista, muy particularmente en su forma actual - y aparte de que este Estado debe ser concebido, de todas maneras, en un sentido amplio concentra cada vez más en él las diversas formas de poder. Interviniendo crecientemente en todas las esferas de la realidad social, disolviendo el tejido social tradicionalmente privado, ese Estado se filtra en las redes más capilares y penetra tendencialmente en los sectores del poder, de todo poder de clase. (Poulantzas, 1979, p. 37).

Assim, longe de possuir alguma neutralidade, o Estado constitui uma relação de condensação de forças, atendendo prioritariamente a frações de classe com maior capacidade de pressão. Ele nem se coloca como um agente todo-poderoso, a quem tudo seria possível, nem tampouco constitui um ente sem qualquer poder. O Estado fica num meio termo e é estratégico como instituição regulamentadora do que pode e do que não se pode, inclusive no que tange ao uso do solo da cidade. A implantação de um determinado projeto urbano é efeito direto desse jogo de forças, e o Estado é agente essencial, seja como regulador, seja ainda como agente financiador, daí que a despeito do protagonismo privado que marca o planejamento urbano no período atual, nem por isso o Estado deixa de ser peça fundamental (Barbosa, 2016).

A produção do espaço é, portanto, marcada por contradições, que têm no Estado um de seus principais agentes, mas não o único. Sejam agentes econômicos ligados aos setores financeiro e imobiliário, sejam agentes ligados a grupos sociais, como coletivos culturais ou mesmo moradores de comunidades pobres, todos esses agentes exercem papel importante na produção do espaço. Outra dimensão de grande importância para a análise da dinâmica urbana diz respeito à compreensão do espaço público, envolvendo sua importância, limites e possibilidades. Sendo assim, nos parágrafos a seguir são feitas reflexões acerca do espaço público, para a crítica às limitações do GPU da zona portuária face à dimensão do direito à cidade.

\footnotetext{
3 Opta-se pelo termo usador ao invés de usuário, uma vez que o sufixo da primeira palavra designa melhor a ação do uso, ao passo que a segunda palavra, muitas vezes, está atrelada ao uso ou acesso a algum espaço mediante o pagamento de taxa. Entende-se, portanto, que, semanticamente, usador tem mais a ver com a apropriação do espaço público.

${ }^{4} \mathrm{~A}$ expressão classe média aqui é usada apenas para identificar as pessoas que compõem a demanda solvente, tais como turistas, frequentadoras dos bares, restaurantes e festas de acesso pago.
} 
Apesar de inúmeras divergências em torno de seu conceito, o espaço público é uma representação da vida urbana. Ele é caracterizado pela forte coexistência de diferentes grupos sociais e seus modos de ser e agir, por isso é por excelência o espaço da heterogeneidade e da convivência. De acordo com Gomes (2012, p. 19), há pelo menos duas acepções para espaço público: "Na primeira, há uma referência concreta a uma área física [...] e uma preocupação prática de planejamento urbano; já no segundo tipo, a referência é a um espaço abstrato, teórico, fundamento da vida política". Tais dimensões do espaço público têm relação direta com as distintas formas de sociabilidade na cidade.

Segundo Gomes (2012), no espaço público, organiza-se uma espécie de cena pública. De fato, os comportamentos, o tipo de vestimenta, as maneiras de falar e de se apresentar, os itinerários percorridos, enfim, tudo que tiver significação nas trocas comunicacionais são elementos que constituem o discurso nessa cena pública. O espaço público é local do ver e ser visto. Durante essa ação, compõem-se imagens, conferem-se valores aos elementos físicos, orientam-se práticas, qualificam-se os comportamentos e são gerados conflitos e reações. Tal cenarização é um processo plural e diverso, pois envolve distintos públicos, e pode, em certos contextos, também ser marcado por relações de conflitos entre distintos atores sociais.

Também se pode dizer que existem dois tipos de espaços públicos, os abertos e os fechados. Conforme Albuquerque (2006), os espaços públicos abertos são áreas situadas dentro de uma concentração urbana, não cobertas por edifícios ou estruturas permanentes, que permitem o livre acesso e o movimento de pessoas sem restrições ou obstruções físicas, cujas atividades se realizam fora da intimidade da habitação. Os espaços fechados representam os edifícios institucionais de uso predominantemente público e comunitário. $\mathrm{O}$ caráter aberto se funda não apenas do ponto de vista da sua estrutura física, de não conter muros, paredes ou qualquer outra forma de barreira física que dificulta ou impede o livre acesso, mas, também, pelo fato de ser, a despeito das diversas formas de vigilância, o espaço de manifestações políticas, culturais, de expressões artísticas e da sociabilidade urbana de distintos grupos sociais.

Por sua vez, mesmo sendo público, tal espaço é regido por regras específicas que cabem às situações que nele ocorrem. Em geral, a fiscalização do cumprimento dessas regras fica por conta do poder público, ainda que isso não ocorra sem a parceria ou a participação indireta de agentes privados. Espera-se civilidade dos usadores dos espaços públicos. Levando em consideração as práticas que ocorrem em certos espaços, os usadores são orientados a ter comportamentos que vão de acordo com as regras de cada espaço público. Para Gomes (2012), os termos que orientam o comportamento não deixam dúvida sobre a sua matriz espacial: civilidade, urbanidade, polidez, todos eles falam dessas condutas formais e ritualizadas, referentes a um espaço urbano que regula as trocas cotidianas entre as diferentes pessoas que dividem esses espaços.

O espaço público não é espaço de pessoas iguais, logo está longe de ser um terreno ou lugar de celebração da isonomia da cidadania, é, segundo esse ponto de vista, o lugar da exclusão, onde determinados grupos são expostos e vistos como não cidadãos ou como subcidadãos (Gomes, 2012). Nem 
todos estão incluídos na rede de direitos e deveres da sociedade. Os moradores da Comunidade do Pilar, por exemplo, mesmo vivendo nas proximidades dos espaços públicos abertos do bairro do Recife, muitas vezes não têm livre acesso ao uso de tais espaços ou não se sentem à vontade para usufruí-los conjuntamente com outros usadores, ainda que aparentemente nada os impeça de usufruí-los.

O sentido mais sublime da cidade enquanto espaço de convivência coletiva, da reunião, do encontro e da festa, dá-se, sobretudo, por meio da sociabilidade urbana manifestada nos espaços públicos. Apesar de ser regido por leis oficiais, o espaço público é permeado de normas definidas simbolicamente pelos citadinos. Se à primeira vista o espaço público parece ser o espaço de ninguém ou onde supostamente se pode fazer tudo, na verdade é justamente o contrário. 0 espaço público é por excelência o espaço do regramento da conduta coletiva, é onde o comportamento de cada indivíduo é balizado pelo que o poder público e a sociedade estabelecem como aceitável e permitido. A inversão dessa premissa gera muitas vezes conflitos no uso e apropriação do espaço público, causando transtornos para a coletividade, que é prejudicada pela ação indevida de alguns indivíduos que simplesmente acham que podem fazer qualquer tipo de uso do espaço público, inclusive degradar os bens que constituem patrimônio coletivo.

Embora tudo isso seja verdadeiro, vale dizer que, por outro lado, há uma dialética do espaço público centrada no fato de ele também ser o espaço da desobediência e da subversão às normas. É justamente por isso que, ao menos nos países sobre regime democrático, o espaço público também se coloca como lócus do confronto e das manifestações políticas, religiosas, culturais, ideológicas de todos os matizes. Enfim, ele tem forte conotação política, pois é onde as diferentes ações e visões de mundo ganham visibilidade.

É comum que os espaços públicos das grandes cidades brasileiras revelem, de modo geral, apropriações seletivas e diferenciadas. Para Serpa (2013), os espaços públicos possuem "leis territoriais" específicas. Nada é exatamente pré-fixado, mas a apropriação diferenciada possui dimensões espaçotemporais que podem ser identificadas por meio do uso cotidiano. Como exemplo disso, é que diferentes grupos podem se apropriar do mesmo espaço público em diferentes horas ou dias. Não por acaso, na cidade contemporânea, a apropriação do espaço público é mediada por processos de territorialização de grupos sociais. Tal fenômeno se manifesta por meio da interposição de recorrentes formas de uso por determinados grupos, os quais, à sua maneira, acabam por estabelecer limites e normas de uso do espaço público, mesmo que muitas vezes de forma tácita. A propósito disso, Serpa (2013, p. 70) ressalta que,

Nos novos e renovados espaços públicos urbanos ao redor do mundo, as práticas espaciais inscrevem-se na territorialização do espaço. Em verdade, os usuários privatizam o espaço público através da ereção de limites e/ou barreiras de cunho simbólico, por vezes, invisíveis. É desse modo que o espaço público se transforma em uma justaposição de espaços privatizados; ele não é partilhado, mas, dividido entre os diferentes grupos e agentes. (Grifos do autor).

Isso posto, é salutar considerar que há práticas e agentes diversos na territorialização dos espaços públicos do bairro do Recife e, muitas vezes, isso resulta em conflitos e contradições. Assim, se de um lado 0 
espaço concebido pela requalificação da zona portuária priorizou a instalação de equipamentos para atender uma demanda solvente ligada ao turismo e ao lazer de pessoas da classe média, de outro, o uso e apropriação das áreas abertas, como a Praça do Marco Zero e o calçadão na frente d'água junto aos armazéns, contam com a participação de pessoas pertencentes a distintos contextos sociais. Para além do que já foi discutido até aqui sobre esse bairro, é relevante reforçar, na seção que se segue, como ele tem sido alvo do planejamento urbano, sendo a requalificação da zona portuária o caso mais recente.

\section{DOS CONTEXTOS PRECEDENTES DO PLANEJAMENTO URBANO ÀS INTERVENÇÕES URBANAS NA ZONA PORTUÁRIA}

O bairro do Recife foi por muito tempo um espaço residencial, habitado por comerciantes, funcionários públicos e trabalhadores do porto, e contava com estabelecimentos de comércio e serviços que atendiam a população local e de outras partes da cidade. Com uso misto, no piso térreo das edificações funcionavam atividades terciárias e na parte superior prevalecia a função residencial. A decadência ocorreu na segunda metade do século XX, tendo se intensificado na década de 1970, com a transferência de grande parte das atividades portuárias para o Complexo Industrial-Portuário de Suape, no litoral sul metropolitano. Foi também nesse período que se deu a saída dos moradores de poder aquisitivo mais elevado para bairros como Graças e Espinheiro, que se verticalizavam (Lacerda, 2007). Em meio a essas mudanças, o bairro do Recife se tornou área de prostituição e de cortiços, ficando por algumas décadas em estado de degradação.

Segundo Lacerda (2007, p. 624), na década de 1970, diante do quadro de degradação urbana, "0 bairro tornou-se uma periferia na centralidade" (grifo da autora), e os primeiros esforços com vistas à recuperação emergiram nos fins da mesma década, com a criação, por parte da Prefeitura, do Escritório do Bairro do Recife. Nos fins da década seguinte, o Governo do Estado elaborou um ambicioso plano de recuperação da economia estadual e elegeu o turismo como uma das atividades-chave para o Recife. Não por acaso, em 1992, foi elaborado o Plano de Revitalização do Bairro do Recife, cujo território foi subdividido em três setores: Setor de Intervenção Controlada, Setor de Renovação e Setor de Consolidação.

Estendendo-se ao longo das instalações do porto e na parte sul, o primeiro setor envolvia o chamado Polo Bom Jesus, possuidor de ruas com um conjunto edificado de forte influência francesa (Lacerda, 2007). 0 segundo setor compreendia o Polo do Pilar, situado na parte central onde se localiza a Comunidade do Pilar e

o Forte do Brum. $O$ terceiro setor correspondia à parte oeste do bairro, fruto de aterro em meados do século XX (Melo, 2003), onde foram construídos órgãos públicos como a Prefeitura, a Polícia Federal e o Tribunal Regional Federal da $5^{a}$ Região, estando aí a parte mais recente do bairro.

Contudo, foi nos anos 1990, com implementação do Programa de Desenvolvimento do Turismo do Nordeste (PRODETUR-NE), que emergiu uma nova fase de reestruturação, com a requalificação da Rua do 
Bom Jesus (Lacerda, 2007). As ações do PRODETUR-NE tinham como foco melhorias urbanas para potencializar o turismo e, na esteira disso, também o consumo da classe média local. Lacerda (2007) ainda ressalta a parceria com a Fundação Roberto Marinho, que viabilizou a implementação do Projeto Cores da Cidade e propiciou a recuperação da pintura da fachada dos edifícios da Rua do Bom Jesus, com evidente propósito de embelezamento do bairro. Tal medida, como bem analisam Nery \& Castilho (2008), mais contribuíram para a gentrificação (parcial, é claro) do que para uma mudança real das condições de vida dos moradores. O bairro do Recife começa a ser reconhecido como um espaço turístico, de eventos culturais e de lazer da cidade do Recife.

Por sua vez, o Programa Monumenta BID viabilizou a requalificação do Polo Alfândega/Madre de Deus, com a recuperação do antigo prédio do Cais da Alfândega, da igreja Madre de Deus e do edifício Chanteclair. Tais intervenções foram realizadas nos fins da década de 1990, com a inauguração do Shopping Paço Alfândega, em 2003. O projeto do shopping incluía ainda uma grande livraria como loja-âncora e, como assevera Lacerda (2007), para atender o cliente de classe média que se desloca cotidianamente por meio do automóvel particular, foi construído um edifício-garagem em dois terrenos vazios integrados por uma passarela sobre a Rua Madre de Deus. O projeto como um todo envolveu questões polêmicas relacionadas à preservação do patrimônio. A construção do edifício-garagem, por exemplo, não respeitou o conjunto paisagístico do lugar, sendo uma demonstração de que forças políticas e econômicas superiores atuaram junto ao IPHAN, em Brasília, para que tal intervenção fosse aprovada tal como ocorreu (Lacerda, 2007; Vieira, 2007). Na prática, a implantação desse projeto urbano é mais uma demonstração do predomínio da visão da cidade como negócio.

Vale frisar, também, a implantação do Porto Digital, que é um núcleo de inovação tecnológica concebido no início da década de 2000 para incubação de empresas do segmento de TI. Trata-se de uma tentativa de promover nova função para a cidade, envolvendo a articulação do Governo do Estado, a academia e a iniciativa privada. Tal política pública aproveitou as boas condições de infraestrutura urbana do bairro do Recife e contou com a grande oferta de imóveis sem uso para a instalação de suas empresas incubadoras. Decorridos vinte anos de sua criação, o Porto Digital se tornou um importante agente imobiliário do bairro (Lacerda \& Fernandes, 2015), ao recuperar imóveis degradados e promover novo uso.

Contudo, foi no contexto dos preparativos para a realização da Copa de 2014 que o bairro do Recife se tornou alvo do mais arrojado projeto de intervenção urbana, o GPU de requalificação da zona portuária, com a implementação dos projetos Porto Novo (equipamentos públicos) e Porto Novo Recife (equipamentos privados). Tal como exibido no Mapa 1, tal GPU resultou na requalificação dos antigos armazéns e na implantação de um parque linear (calçadão) ao longo do cais do porto, o que ampliou a oferta de equipamentos de lazer e a oportunidade de os agentes econômicos fazerem novos negócios a partir da e na cidade, no âmbito desse bairro. Por meio do Projeto Porto Novo, a requalificação dos armazéns 7 e 8 deu origem ao Terminal Marítimo de Passageiros; na localização do armazém 10 foi construído o Museu Cais do 
Sertão; no armazém 11, o Centro de Artesanato de Pernambuco. Por sua vez, os equipamentos privados foram implantados nos armazéns $9,12,13,14,15,16$ e 17. Notícia divulgada pelo Diário de Pernambuco, em 10 de março de 2020, informa que as obras referentes à localização dos três últimos armazéns foram oficialmente anunciadas pelos empreendedores privados e o governo estadual, tendo previsão de conclusão no primeiro semestre de 2022 (Diário de Pernambuco, 2020).

Vale frisar que, a rigor, as intervenções na zona portuária do Recife não contêm nada de novo em si, pois repetem cases de outras cidades, a exemplo de Barcelona e Rio de Janeiro, como parte de um processo de empresariamento urbano que se manifesta na escala mundial. Desse modo, megaprojetos urbanos e megaeventos são cada vez mais duas faces de uma mesma moeda: os grandes interesses econômicos que veem a metrópole como espaço privilegiado da acumulação capitalista. Ressalvadas as devidas proporções da dinâmica econômica do Recife, o GPU em contexto é apenas mais um entre tantos outros casos de intervenção com viés de empresariamento urbano em áreas históricas. Nos próximos parágrafos é feita uma breve análise sobre cada empreendimento.

O Terminal Marítimo de Passageiros foi concluído em outubro de 20135. O total de gastos com tal intervenção ficou em $\mathrm{R} \$ 28,8$ milhões, advindos de parceria entre o Governo do Estado de Pernambuco e o Programa de Aceleração do Crescimento Copa - PAC Copa. Outras capitais, como Salvador, Natal, Fortaleza e Manaus, também tiveram a requalificação nos seus terminais fluviais, sendo o de Recife o primeiro a ser entregue. Com estrutura de aço e vidro na parte externa, a arquitetura do edifício do terminal não dialoga com o conjunto paisagístico do entorno (Figura 02), o que, diga-se de passagem, não constitui novidade no bairro do Recife. Segundo informação disponível no site do Porto do Recife, o terminal possui uma área total de 7,9 mil $\mathrm{m}^{2}$ e uma capacidade para três navios de grande porte atracados e uma média de circulação de 4 mil pessoas ${ }^{6}$. Porém, ao se alegar que seria necessário uma dragagem para receber navios de grande porte, 0 número de navios de turismo que chegam ao Recife é muito pequeno, resultando em prejuízo por conta da subutilização desse equipamento nos dias atuais?

\footnotetext{
5 Disponivel em: https://gauchazh.clicrbs.com.br/geral/noticia/2013/10/prevista-para-fevereiro-abertura-do-terminal-maritimo-dorecife-sera-no-domingo-4297866.html. Acessado em: 06 maio. 2019.

${ }_{6}$ Disponível em: http://www.portodorecife.pe.gov.br/noticia-int.php?id=terminal-maritimo-de-passageiros2. Acessado em: 06 maio 2019.

7 Disponivel em: http://g1.globo.com/pernambuco/noticia/2014/12/audiencia-poe-em-xeque-viabilidade-de-terminal-maritimo-dorecife.html. Acessado em: 06 maio 2019.
} 


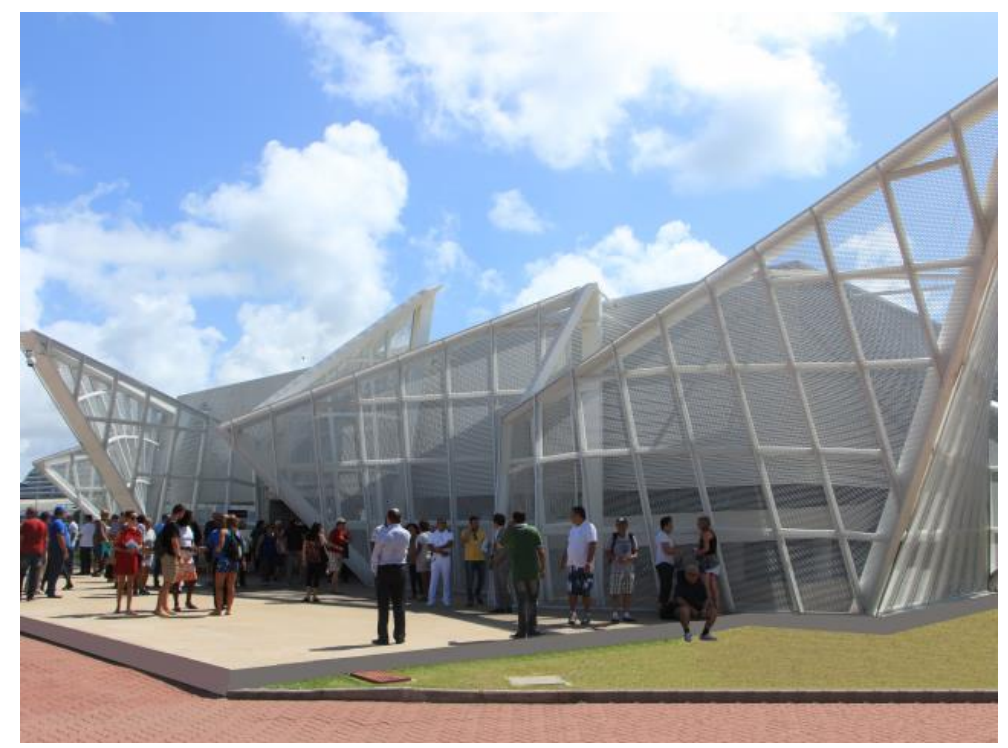

Figura 02 - Terminal Marítimo de Passageiros do Recife.

Fonte: Porto do Recife. Disponível em:

http://www.portodorecife.pe.gov.br/terminal_operacoes.php. Acessado em: 06 fev 2020.

Outra importante obra do Projeto Porto Novo foi a implantação do Museu Cais do Sertão, no Armazém 10, iniciada em 2010 (Figura 03). Foi a obra mais cara de todo o projeto, com uma média de R\$ 120 milhões em investimentos públicos e privados. A concepção do museu, segundo entrevista concedida pela representante da Coordenação de Conteúdo, foi inspirada no Museu da Língua Portuguesa, situado na cidade de São Paulo, tendo a finalidade de homenagear a cultura sertaneja do Nordeste brasileiro e a obra de Luiz Gonzaga. O primeiro módulo foi inaugurado no ano de 2014, contando com um espaço de $2.000 \mathrm{~m}^{2}$, com a exposição permanente chamada "O Mundo do Sertão".

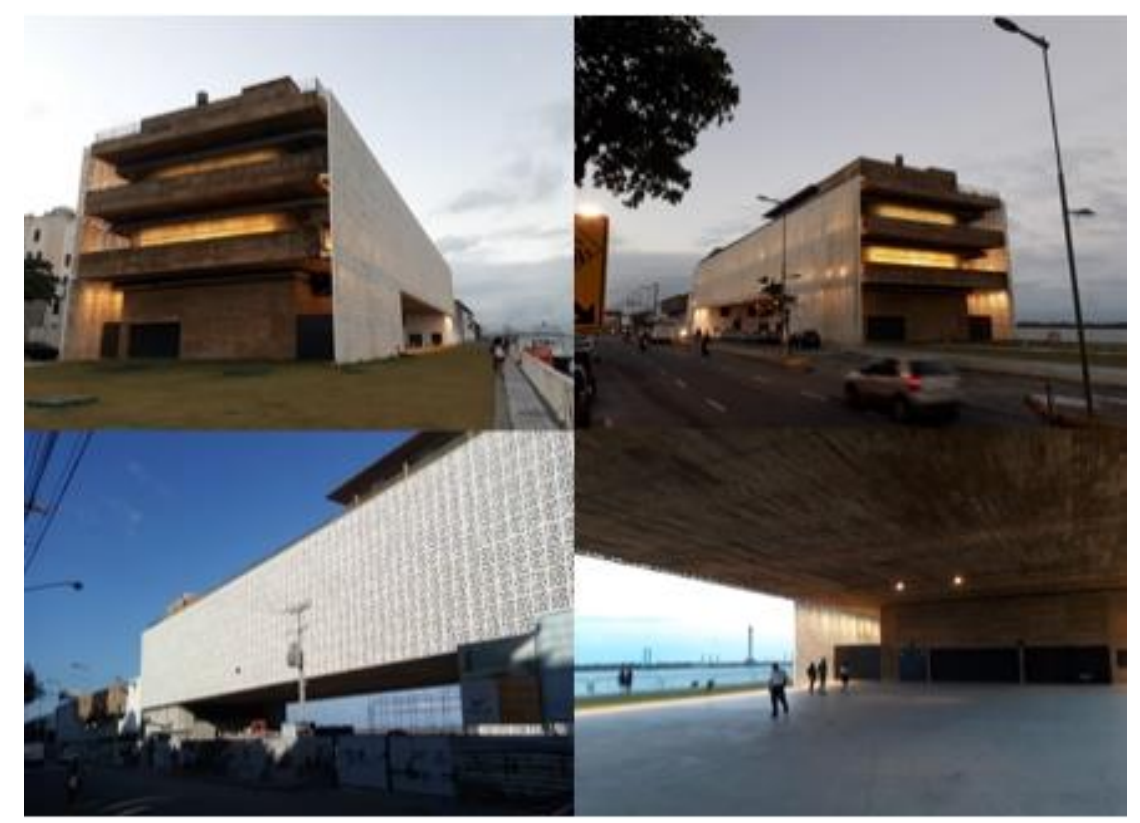

Figura 03 - Vista externa do Museu Cais do Sertão. Fonte: Felipe Marangoni, nov./2018. 
O museu está inserido no âmbito da economia criativa e uma de suas funções é fazer parcerias com outras instituições culturais, inclusive outros museus, como forma de promover a educação não formal, particularmente por meio da vertente cultural. Trata-se, como se vê, de um equipamento fundamental, cuja importância vai muito além do mero discurso do "desenvolvimento do turismo", como muitas vezes se alega como suposta justificativa de implantação de um museu desse porte. É importante que se diga que os museus em geral, ou o Cais do Sertão em particular, não podem ser concebidos apenas como intervenções de impacto visual na paisagem urbana, eles precisam ter sua função mais nobre: funcionarem efetivamente como equipamentos de promoção da cultura.

De acordo com a coordenação do Museu Cais do Sertão, os picos de visitação ocorrem nos meses das férias escolares, chegando a uma média de 16 mil visitantes por mês. Com a conclusão do segundo módulo em meados de 2018 e que contou com investimento de R 25 milhões, seus gestores asseguram que as atividades deverão ficar ainda mais versáteis, visto que o equipamento conta com: sala de reserva técnica; 4 salas de exposição temporárias; auditório com 230 lugares; 01 restaurante no terraço e um vão aberto inspirado no Museu de Arte de São Paulo - MASP, com 60m². Contudo, não se deve perder de vista que esse museu é um objeto espacial concebido num quadro de valorização do bairro do Recife. Sob a égide do city marketing, a requalificação de áreas históricas tem sido marcada em várias cidades, no Brasil e no mundo, pela implantação de museus e equipamentos de lazer, funcionando como ferramenta de estímulo do turismo.

Outro equipamento do Projeto Porto Novo é a segunda unidade do Centro de Artesanato de Pernambuco ${ }^{8}$. Construído no antigo Armazém 11, foi a primeira obra do Projeto Porto Novo a ser entregue, em setembro de 2012, e está sob a gestão da Secretaria de Desenvolvimento Econômico do Estado de Pernambuco. De forma semelhante ao Cais do Sertão, também funciona como um equipamento de promoção da cultura. Com acesso frontal para o Marco Zero, volta-se para a comercialização de produtos artesanais, fato positivo por dar visibilidade ao trabalho de artesãos que produzem em todas as regiões do estado e propiciar a comercialização de suas peças.

Tal iniciativa parece indicar uma boa saída no que tange à intervenção em edificações públicas outrora sem uso, porém, observou-se que o quadro de pessoal que trabalha lá poderia, por meio de ações de capacitação, aproveitar jovens aprendizes e até mesmo adultos moradores da vizinha Comunidade do Pilar e de outras áreas pobres do entorno do bairro do Recife, mas não há o aproveitamento dos moradores dessa comunidade em ações e projetos empreendidos no próprio bairro.

Os Armazéns 12 e 13, por sua vez, foram destinados ao segmento de bares e restaurantes, com algumas franquias se estabelecendo no local, que desfrutam da amenidade dos espelhos d'água do rio e do

\footnotetext{
8 Inaugurada em 2003, a primeira unidade do Centro de Artesanato de Pernambuco localiza-se na cidade Bezerros, no Agreste pernambucano, sendo composta por loja, museu e auditório para 200 pessoas.
} 
oceano. Há ainda um calçadão que funciona como parque linear que se converteu num importante espaço público do bairro. É lamentável que microempreendedores que comercializam produtos diversos na Feirinha da Rua do Bom Jesus, durante os domingos, não tenham sido contemplados entre os beneficiários diretos dessa intervenção. De acordo com um representante deles, sequer foram convidados para dialogar sobre 0 porte e os usos que seriam dados a esses estabelecimentos, o que descartou por completo sua eventual participação. Como o espaço foi concebido para a classe média, tais comerciantes não se encaixam nesse perfil, deixando evidente o caráter seletivo do projeto.

O Armazém 14, por sua vez, embora estivesse previsto na concepção inicial do Projeto Porto Novo Recife para abrigar sala de cinema/teatro e um boliche, sofreu mudança e funciona atualmente como casa de show. Chamado de Armazém Itaipava Catorze e sob a gestão do Grupo Petrópolis, dono da cerveja Itaipava, tal equipamento possui uma estrutura climatizada, um espaço útil de $1.900 \mathrm{~m}^{2}$ e conta com dois pavimentos internos, o térreo e o mezanino, além de uma varanda para o espelho d'água.

Um dos argumentos apontados pelo Grupo Petrópolis é que tal equipamento serviria para promover a valorização dos movimentos culturais. Ora, os concertos musicais que comumente acontecem sob tal tipo de patrocínio atendem tão somente os interesses do mercado, não havendo nada de diferente nesse caso, pois não há qualquer engajamento cultural mais profundo com as expressões artísticas e culturais locais. São concertos que não têm nada de diferente dos que acontecem em outros espaços comerciais do próprio Recife ou de qualquer outra cidade brasileira, tendo como objetivo primordial apenas o retorno financeiro dos eventos que realizam.

Vale frisar que funcionava no Armazém 14 um grupo de teatro independente, o qual encerrou suas atividades no ano de 2011, fechando um trabalho de 11 anos, devido, justamente, às obras de requalificação. Tal fato gerou descontentamento dos artistas locais e deixa evidente o viés de empresariamento urbano do Projeto Porto Novo Recife. Mesmo que promovam a cultura local, projetos e iniciativas de grupos não hegemônicos são barrados ao sabor dos interesses empresariais.

Desse modo, coletivos de artistas alternativos perdem seus espaços de expressão cultural diante do peso que uma importante cervejaria e seus parceiros exercem sobre o poder público. É contraditório que tal fato tenha ocorrido justamente num dos bairros mais evocados como lócus de manifestações culturais de Pernambuco. À medida que coletivos culturais são "expulsos" de áreas históricas para ceder lugar à atuação de empresas de eventos apoiadas unicamente na lógica do lucro, torna-se o lugar mais pobre do ponto de vista da cultura. Trata-se de um aspecto muito grave e por isso a requalificação dos armazéns não deveria ser tratada como uma simples questão de recuperação urbana e de criar ambiente de negócios, tal como vem acontecendo.

Outra intervenção integrante do Projeto Porto Novo Recife é o estacionamento na área onde funcionava o Armazém 15. A priori, esse espaço foi projetado para ser uma área arborizada com mirantes para o espelho d'água, mas, foi modificado pela Prefeitura, pelo IPHAN e pelo consórcio que administra 0 
local e virou um estacionamento nos dias úteis. 0 ganho de mais 450 vagas para estacionamento mostra que, à semelhança, do que foi feito em relação ao Shopping Paço Alfândega, o foco principal é o frequentador de classe média que se desloca de automóvel particular. 0 estacionamento tem dois pavimentos, sendo 0 superior também usado para eventos, conhecido como Parador, com acesso pago, inclusive, nas datas festivas, como carnaval e réveillon, ou em qualquer data do ano.

Além dos equipamentos já implantados, o Projeto Porto Novo Recife contempla ainda a implantação de um complexo multiuso com hotel, marina e centro de convenções na área correspondente aos armazéns 16 e 17, na parte situada no bairro de São José. Esses empreendimentos serão vizinhos dos polêmicos edifícios Píer Maurício de Nassau e Pier Duarte Coelho (Torres Gêmeas), edifícios residenciais com 42 andares cada um e que destoam por completo da paisagem histórica do bairro de São José.

Tais etapas do Projeto Porto Novo Recife estavam embargadas pela Justiça Federal, mas, superado esse entrave, o governo estadual e os empreendedores anunciaram que as obras poderiam ter início ainda no primeiro semestre de 2020 (Diário de Pernambuco, 2020). Independentemente da concretização ou não desta última etapa, a requalificação da zona portuária do Recife revela a perspectiva de empresariamento urbano com toda sua força. Tal como o projeto como um todo, ela é imposta à cidade, colonizando visões e mentes dos citadinos (ou pelo menos da maior parte deles), os quais, muitas vezes, defendem tais intervenções sob o discurso da geração de emprego e renda, ou ainda pelo prisma do suposto embelezamento que elas promoveriam na paisagem da cidade.

\section{CONFLITOS E CONTRADIÇÕES NO USO DO ESPAÇO PÚBLICO}

Conforme discutido anteriormente, o espaço público é, por excelência, o espaço da copresença e isso tanto o torna lócus de diversidade de modos de viver a cidade, como, em certas vezes, é marcado pela intolerância e estranhamento entre os seus usadores. Embora o bairro do Recife tenha outros espaços públicos, faz-se aqui uma análise da apropriação de duas áreas abertas no contexto do GPU da zona portuária: a Praça do Marco Zero e o parque linear constituído pelo calçadão situado entre os casarões 12, 13, 14 e 15, à margem do espelho d'água do estuário do Rio Capibaribe. Trata-se de espaços públicos muito integrados e de maior circulação de pessoas no contexto do bairro. Ressalta-se que a requalificação do Marco Zero data do ano 2000, sendo anterior ao projeto urbano em contexto, mas que, na prática, se tornou parte dele, já que está situado na zona portuária, entre os armazéns requalificados. Contudo, vale frisar que ocorrem manifestações culturais em outros pontos do bairro, principalmente nos fins de semana, envolvendo apresentações de grupos de maracatu, frevo, capoeira, apresentações musicais, dentre outras expressões.

No caso da Praça do Marco Zero e do calçadão, vários grupos principalmente de jovens se apropriam do espaço público. São jovens que se reúnem para dançar o passinho, conversar, ouvir música, namorar, 
dentre outras práticas que se traduzem em formas de lazer e de sociabilidade, sobretudo nos fins de semana. Em alguns casos há mesmo uma territorialização do espaço público por esses grupos (Neves, 2018), em que praticantes de esportes, para delimitar seu espaço, chegam mais cedo para posicionar, na praça ou no calçadão, instrumentos das respectivas modalidades de esportes e, assim, demarcar seu território. Trata-se da territorialização nos termos abordados por Serpa (2013), conforme já discutido.

O consumo de bebidas alcoólicas é a segunda atividade mais praticada nesse espaço público. Realizada por jovens fora dos bares, é, muitas vezes, coibido pelo poder público. Conforme disse um representante da Prefeitura do Recife, esse público - jovens "periféricos" - não é interessante para o bairro, devido ao (suposto) risco de violência que ele pode oferecer e por não consumir nos estabelecimentos formais. No entanto, esses jovens são o público consumidor dos vendedores ambulantes do bairro e, legalmente, são tão cidadãos como outros frequentadores do bairro. Percebe-se que é constante a presença de guardas municipais para revistar esses grupos, principalmente quando insistem em permanecer em frente aos estabelecimentos dos armazéns 12, 13 e 14 (Figura 04), setor dos bares e restaurantes mais frequentados pela dita classe média. Como se vê, a copresença, característica primordial do espaço público, não é tolerada por determinados agentes sociais.

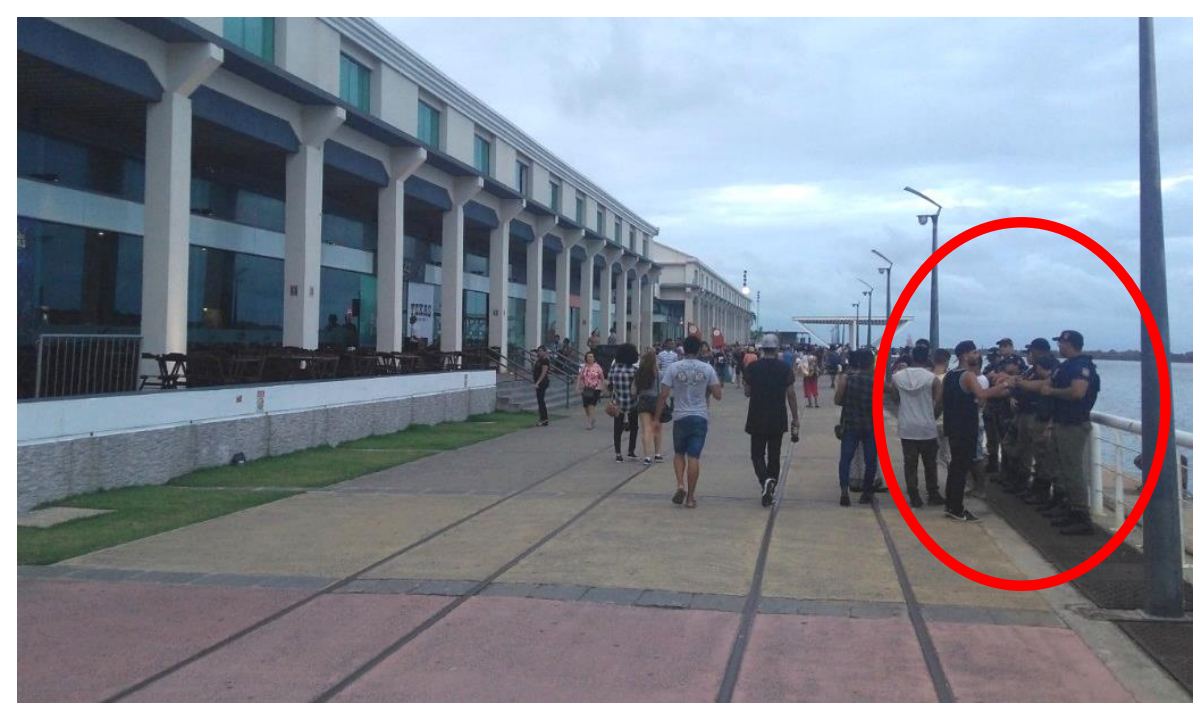

Figura 04 - Agentes da Guarda Municipal do Recife abordando usadores do bairro. Fonte: Gustavo Maciel, mar/2018.

Outros grupos também sofrem com a atuação do poder público. De acordo com entrevistas realizadas com praticantes de esportes no espaço público do bairro, nos anos de 2014 e 2015, período em que os novos empreendimentos passaram a funcionar, o poder público restringia o uso do skate no Marco Zero e no calçadão, alegando que o objeto poderia destruir o piso. No âmbito da apropriação do espaço público, há o conflito gerado pela restrição/vigilância dos agentes de segurança pública sobre as práticas espaciais consideradas "não desejadas" para aquela área concebida para a classe média. Revela-se aí a contradição entre a dimensão do concebido e a do vivido, já que uns são bem-vindos àquele espaço público e outros não. 
Isso posto, nota-se que tal requalificação tem contribuído, em certo sentido e de forma contraditória, para o empobrecimento da sociabilidade urbana no espaço público, ainda que isso não deva ser encarado em sentido estrito, pois o bairro do Recife continua a apresentar forte conteúdo de sociabilidade urbana, apesar dessa tentativa de homogeneização do perfil dos usadores. Como se vê, as reflexões teóricas sobre o espaço público ajudam a pensar acerca dos conflitos que emergem nas duas áreas analisadas. Longe de se lançar como uma suposta "solução" para o bairro outrora degradado, a requalificação da zona portuária parece potencializar novos (velhos!) problemas, que apenas se tornam mais evidentes com as intervenções urbanísticas seletivas e homogeneizadoras.

\section{CONSIDERAÇÕES FINAIS}

As intervenções implantadas demonstram que os planos e projetos concebidos para o bairro do Recife expressam a intencionalidade de recuperar estruturas degradadas para a promoção de novos usos e a dinamização econômica desse espaço estratégico da cidade. Assim, em que pesem fortes críticas sobre a natureza mercadológica dessas intervenções, em certo sentido parece razoável considerar o papel delas sob o ponto de vista da conservação urbana. Vale destacar, portanto, o lado positivo da requalificação, mas ao mesmo tempo cabe questionar para quem a cidade está sendo planejada e requalificada. 0 planejamento urbano, neste caso, "teima", tal como experiências anteriores para o próprio bairro do Recife, em revitalizar e requalificar as estruturas degradadas de forma seletiva, ou seja, para segmentos da classe média, como se a cidade não fosse também e de forma predominante constituída por moradores de baixo poder aquisitivo.

Em decorrência disso, também ficou evidenciado que as intervenções urbanas no âmbito do GPU da zona portuária do Recife reforçam o caráter homogeneizador apresentado pelos espaços turísticos e de consumo da classe média, em função das matrizes do planejamento que são adotadas. Nesse sentido, busca-se a adequação da cidade a atividades essenciais para a acumulação urbana e, no caso analisado, está muito atrelado a ações que visam fortalecer o turismo, o lazer e a economia criativa. Desde a criação do Escritório do Bairro do Recife, nos anos 1970, passando pelas intervenções na Rua do Bom Jesus e no Cais da Alfândega, até as transformações mais recentes na zona portuária, tudo isso expressa um esforço do poder público e de agentes privados para que, de fato, o bairro do Recife se converta num espaço de consumo voltado para o lazer e de negócio no contexto do Recife e, de fato, tem se tornado, a despeito de algumas experiências fracassadas.

Contudo, vale frisar um quadro mais real da cidade que também se manifesta com a requalificação da zona portuária do bairro do Recife. Ainda que o lado econômico seja o principal direcionador das intervenções, não se pode deixar de reconhecer a inserção desse bairro como lócus de manifestações sociais e culturais que o tornam muito vivo no contexto da cidade. Por esse fato, o seu espaço público é marcado por uma grande diversidade de usadores e forte centralidade de manifestações culturais. Sendo assim, mesmo 
que as intervenções sejam seletivas, as áreas livres do bairro, como o Marco Zero e o calçadão junto aos armazéns, são, a despeito de interesses em contrário, lócus da copresença de diferentes atores e grupos sociais e de manifestações diversas, o que atesta a riqueza do espaço público.

Desse modo, os espaços públicos estudados, mesmo que concebidos para um lazer programado, são, na prática, também uma alternativa de lazer e de sociabilidade urbana para os ditos "periféricos", moradores de diversas partes do Recife e de outras cidades da área metropolitana. À sua maneira, grupos de maracatu, passinho, capoeira, por exemplo, promovem um lazer "desprogramado" e sem grandes pretensões, posto que não figurava entre os usos previstos nos planos e projetos. Constatou-se que muitos dos grupos sociais que se apropriam do espaço público do bairro do Recife resistem e se apropriam das áreas livres e as transformam num espaço de diversidade e de convivência entre os diferentes, ainda que isso por vezes resulte em tensões. A despeito dos desafios e problemas a serem enfrentados, a vida urbana do bairro do Recife também parece apontar algumas iniciativas instigantes para se pensar a cidade do ponto de vista do uso e apropriação do espaço público, faltando, muitas vezes, um olhar mais plural do próprio poder público.

\section{REFERÊNCIAS}

Albuquerque, M. Z. A. de. (2006) Espaços livres públicos inseridos na paisagem urbana: memórias, rugosidades e metamorfoses. Estudo dos parques urbanos 13 de Maio, Recife-Brasil e do Tiergarten, Berlim-Alemanha. (Dissertação de Mestrado).

Retrieved from: https://repositorio.ufpe.br/handle/123456789/6867

Barbosa, A. G. (2016). Planejamento urbano empresarialista em complexos imobiliários, residenciais e de serviços: a Reserva do Paiva em análise [Entrepreneurial urban planning in real estate, residential and servisse complexes: Reserva do Paiva under analysis]. Cadernos Metrópole, v. 18, n. 37. Doi: http://dx.doi.org/10.1590/2236-9996.2016-3708.

Bataller, M. A. S. Botelho, M. L. (2012). O Estudo da Gentrificação [The study of gentrification]. Revista Continentes, [S.I.], n. 1. ISSN 2317-8825. Retrieved from:

http://www.revistacontinentes.com.br/continentes/index. php/continentes/article/view/5

Bresser-Pereira, L. C. (1998). Reforma do Estado para a cidadania: a reforma gerencial brasileira na perspectiva internacional. [State refor for citizenship: Brazilian manegement reform from na international perspective] São Paulo: Editora 34; Brasília: ENAP.

Carlos, A. F. A. (2001). Espaço-tempo na metrópole: a fragmentação da vida cotidiana. [Space-time in the metropolis: the fragmentation of the everyday life] São Paulo: Contexto.
Diário de Pernambuco. Investimento de $R \$ 140$ mi e geração de emprego com complexo multiuso.

Retrieved from:

https://www.diariodepernambuco.com.br/noticia/econo mia/2020/03/investimento-de-r-140-mi-e-geracao-deemprego-em-complexo-multiuso.html .

Castro, I. E. de., Gomes, P. C. da C., \& Corrêa, R. L. (2012). Espaços públicos: um modo de ser do espaço, um modo de ser no espaço. [Public Spaces: a way of being from the space, a way of being in the space]. Olhares geográficos: modos de ver e viver o espaço. Rio de Janeiro: Bertrand Brasil, 2012, 19-41.

Lacerda, N. (2007) Intervenções no bairro do Recife e no seu entorno: indagações sobre a sua legitimidade. [Interventions in Recife's neighborhood and surroundings: investigations of legitimacy] Sociedade e Estado, v. 22, n. 3, 621-646. Retrieved from: https://www.scielo.br/scielo.php?pid=S010269922007000300006\&script=sci_abstract Lacerda, N., \& Fernandes, A. C. (2015). Parques tecnológicos: entre inovação e renda imobiliária no contexto da cidade do Recife [Technology parks: between innovation and real estate rents in the context of Recife, Brazil]. Cadernos Metrópole, São Paulo, v. 17, n. 34, 329-354. Retrieved from: http://dx.doi.org/10.1590/2236-9996.2015-3402.

Lefebvre, H. (2001). O direito à cidade. [The right to the city] São Paulo: Centauro. 
Lefebvre, H. (2007). The production of space. Oxford: Blackwell Publishing.

Lefebvre, H. (2008). Espaço e política. [Space and Politic]. Belo Horizonte: UFMG.

Melo, J. M. de. (2003) Programa de Requalificação Urbanística e Inclusão Social da Comunidade do Pilar. (Dissertação de Mestrado).

Mendonça, A. S. (2014). Grandes projetos urbanos e gestão pública: a renovação da área portuária do Recife. (Dissertação de Mestrado). Retrieved from: https://repositorio.ufpe.br/handle/123456789/17743

Nery, N. S., \& Castilho, C. J. M. de. (2008) Comunidade do Pilar e a Revitalização: possibilidades de inclusão socioespacial dos moradores ou gentrificação. [Comunidade do Pilar and the revitalization: possibilities of socialspatial inclusion of residents or gentrification]. Revista Humanae, v. 1, n. 2. Retrieved from:

http://humanae.esuda.com.br/index.php/humanae/articl e/view/59

Neves, G. M. M. das. (2018) Cenarização da vida urbana: apropriações e territorialização do espaço público no Marco Zero, bairro do Recife-PE. (Monografia de graduação).

Poulantzas, N. (1979). Estado, Poder y Socialismo. Madri: Siglo XXI de España Editores.

Serpa, A. (2013). Microterritórios e segregação no espaço público da cidade contemporânea.

[Microterritories and segregation um the public space of the contemporary city]. Cidades, v. 10, n. 17, 62-75, Retrieved from:

http://revista.fct.unesp.br/index.php/revistacidades/articl e/view/3235/2748.

Souza, F. A. M. de., \& Cavalcanti, A. C. R. (2013). A euforia do capital. Muito além da demanda solvente. [The euphoria of capital. Far beyond solvent demand]. Anais: Encontro Nacional da ANPUR, v, 15.

Vieira, N. M. (2007). Gestão de sítios históricos: a transformação dos valores culturais e econômicos em programas de revitalização em áreas históricas [Management of historic sites: the transformation of cultural and economic values into revitalization programs in historic áreas]. Recife: UFPE. 